\title{
Investigating the Role of Alkyl Chain Length of the Inhibitors on Its Intercalation Inhibiting Mechanism in Sodium Montmorillonite
}

\author{
Gang Xie*, Danchao Huang, Mingyi Deng, Pingya Luo**
}

State Key Laboratory of Oil \& Gas Reservoir Geology and Exploitation, Southwest Petroleum

University, Chengdu, Sichuan 610500, China.

\section{Supporting Information}

\section{Elemental analysis}

Fig. S1 shows the results of the elemental analysis of Na-MMTinhibitor complexes. Nitrogen is a characteristic element in the Na-MMT- inhibitor complexes. Each inhibitor molecule contains two nitrogen atoms. The nitrogen content of the inhibitor can be quantitatively determined by measuring the $\mathrm{Na}$ MMT- inhibitor complexes, and verifying the results of the isothermal adsorption. Table 4 shows that the proportion of nitrogen was the maximum at a low concentration of the inhibitor $(0.5 \% \mathrm{w} / \mathrm{w})$. The proportion of nitrogen did not change when the concentration of the inhibitor was increased, indicating that the saturated adsorption content of the adsorbed inhibitor was less than $0.5 \%(\mathrm{w} / \mathrm{w})$. The proportionate order of nitrogen in the inhibitors are $\mathrm{C} 8<\mathrm{C} 7<\mathrm{C} 6<\mathrm{C} 5<\mathrm{C} 4<\mathrm{C} 3$ $<\mathrm{C} 2$, indicating that as the alkyl chain length increases, the nitrogen proportion gradually decreases. The saturated adsorption capacity of the inhibitors of Na-MMT decreased with the increase in the alkyl chain length. 
S1 The nitrogen proportion of inhibitor adsorbed on the Na-MMT at different concentrations

\begin{tabular}{|c|c|c|}
\hline Inhibitors & Concentration wt $\%$ & $N(A t \%)$ \\
\hline \multirow{8}{*}{$\mathrm{C} 2$} & 0.50 & 2.84 \\
\hline & 1.00 & 2.83 \\
\hline & 1.50 & 2.85 \\
\hline & 2.00 & 2.86 \\
\hline & 2.50 & 2.83 \\
\hline & 3.00 & 2.84 \\
\hline & 3.50 & 2.85 \\
\hline & 4.00 & 2.86 \\
\hline \multirow{8}{*}{$\mathrm{C} 3$} & 0.50 & 2.66 \\
\hline & 1.00 & 2.64 \\
\hline & 1.50 & 2.65 \\
\hline & 2.00 & 2.67 \\
\hline & 2.50 & 2.67 \\
\hline & 3.00 & 2.64 \\
\hline & 3.50 & 2.65 \\
\hline & 4.00 & 2.66 \\
\hline \multirow{8}{*}{$\mathrm{C} 4$} & 0.50 & 2.14 \\
\hline & 1.00 & 2.15 \\
\hline & 1.50 & 2.13 \\
\hline & 2.00 & 2.14 \\
\hline & 2.50 & 2.14 \\
\hline & 3.00 & 2.16 \\
\hline & 3.50 & 2.15 \\
\hline & 4.00 & 2.14 \\
\hline \multirow{8}{*}{$\mathrm{C} 5$} & 0.50 & 2.05 \\
\hline & 1.00 & 2.06 \\
\hline & 1.50 & 2.04 \\
\hline & 2.00 & 2.05 \\
\hline & 2.50 & 2.06 \\
\hline & 3.00 & 2.04 \\
\hline & 3.50 & 2.07 \\
\hline & 4.00 & 2.05 \\
\hline \multirow{8}{*}{ C6 } & 0.50 & 1.91 \\
\hline & 1.00 & 1.9 \\
\hline & 1.50 & 1.92 \\
\hline & 2.00 & 1.91 \\
\hline & 2.50 & 1.90 \\
\hline & 3.00 & 1.91 \\
\hline & 3.50 & 1.92 \\
\hline & 4.00 & 1.90 \\
\hline
\end{tabular}




\begin{tabular}{ccc}
\hline Inhibitors & Concentration wt $\%$ & $\mathrm{~N}(\mathrm{At} \%)$ \\
\hline & 0.50 & 1.85 \\
$\mathrm{C} 7$ & 1.00 & 1.85 \\
& 1.50 & 1.85 \\
& 2.00 & 1.85 \\
& 2.50 & 1.85 \\
& 3.00 & 1.85 \\
& 3.50 & 1.85 \\
& 4.00 & 1.85 \\
\hline & 0.50 & 1.81 \\
$\mathrm{C} 8$ & 1.00 & 1.80 \\
& 1.50 & 1.81 \\
& 2.00 & 1.82 \\
& 2.50 & 1.82 \\
& 3.00 & 1.80 \\
& 3.50 & 1.81 \\
& 4.00 & 1.82 \\
\hline
\end{tabular}

